\title{
Influence of the Thermal Field on Static Behaviour of Sandwich Structures
}

\author{
ELENA-FELICIA BEZNEA, GELU COMAN, NICUSOR BAROIU*, IONEL CHIRICA \\ Dunarea de J os University of Galati, 47 Domneasca Str., 800008, Galati, Romania
}

\begin{abstract}
In this paper, numerical and experimental studies on the influence of the thermal field on behavior of the structure of sandwich plates in three points bending is analysed. Various materials are used so for skins. For the core only extruded polystyrene, with various thicknesses is used. The thermal conductivity $v$ was determined by using the Hilton B480 unit, based on the heat flowmeter method described in ISO 8301:1991. We have been analyzed 12 cases of composite sandwich structures. The results obtained by experimental determination and numerical simulation of all cases of modeling are compared and certain differences occurred on the analyzing of influence of the thermal field on the bending characteristics of sandwich structures.
\end{abstract}

Key words: sandwich panel, finite elements method, thermal analysis, bending analysis.

Maintenance costs during the life-cycle of some materials used in industrial fields are depending on the mechanical characteristics, the operational conditions, as well as ambiental temperatures, constantor variable loads, vibrations etc., resulting in a more careful and varied choice of materials, reinforced by testing and simulations of their behaviour under conditions as close to those encountered in service. Sometimes, the composites are using for energy conservation in buildings, to reduce the heating loads and especially the cooling loads. Nowadays, a significant number of modern insulation materials, such as extruded polystyrene are characterized by their very low thermal conductivity factor and good overall performance in terms of physical properties (stiffness and strength) - [1]. In certain industries, such as shipbuilding, the sandwich composite panels are used for the both special characteristics to be fulfilles in the same time: used as strength structural elements and as thermal insulation panels.

Depending on the temperature gradient, the influence of the thermal loading can have a significant influence on the global strength of the sandwich panel.

Specimens of sandwich panels have been fabricated from foam cores (extruded polystyrene), aluminum, steel and e-glass polyester fiber skins. Simulations of plate bending behavior and through-thickness thermal conductivity have been performed with these specimens. The resulting data have been used to validate numerical models.

Modern sandwich panels, which consist of a low strength flexible core and two face sheets that are either made of metal or composite laminated materials, are widely used in the aerospace, naval, transportation and building industry [2-3]. They are used as primary and secondary structural components, and their popularity is a result of their superior qualities in terms of weight to strength ratio, high stiffness, ease of manufacturing, acoustic and thermal insulation [4].

The thermal and the thermo-mechanical response of a flat sandwich panel with a compliant core has been considered by Frostig and Thomsen in [5]. Thermal effects in sandwich panels behaviour have been considered in certain papers, assuming simplified computational models [6-7].

The design process of sandwich structures is considering the responses due to the thermal loading, but the deformations induced by thermal field are considered separately by those induced by mechanical loads [8]. However, the interaction between the mechanical and thermal loads may lead to special behaviour, such as buckling and loss of structural integrity. These situations occur especially when the deformations are large and the mechanical features degrade as the temperature level is increasing. Also, important degradation of the foam properties occurs at extremely temperatures [9].

The numerical studies investigate the response of sandwich panels subjected to mechanical concentrated loads $(F=60 N)$, and simultaneous thermal and mechanical charges.

The loss in stiffness of this types of core changes the overall mechanical response of the panel sandwich structure [10-11]. This change in panel behaviour has to be considered in the design procedures, because it may lead to a significant change in the failure mode of the structure [12-13].

In this paper, the influence of the thermal loads on the static bending behaviour of the composite sandwich panels is analysed. Analysis is focused on the bending behaviour of two types of specimens having differend thicknesses. Bending of a sandwich beam subjected to a three-point bending was analysed in two cases: at the room temperature and with a uniform through-the-thickness temperature. The numerical results have been analysed for two core thicknesses values confirming a uniform distribution of the transverse shear stress through the thickness of the core. The response of sandwich beams subject to a combined thermomechanical load was further investigated.

\section{Experimental part}

Fabrication stages for obtaining a composite sandwich panel

The specimens have been built as a sandwich panel with two face sheets ( $3 \mathrm{~mm}$ thickness each of them) from glass thread with a weight of $300 \mathrm{~g} / \mathrm{m}^{3}$ and $450 \mathrm{~g} / \mathrm{m}^{3}$, extruded polystyrene core with the density of $30 \mathrm{~kg} / \mathrm{m}^{3}$. Prepregging has been achived with epoxy with a density of $1.1 \mathrm{~kg} / \mathrm{dm}^{3}$. The glass thread used on such a panel is one of high stiffness called STRATIMAT. The first layer consists of a STRATIMAT-veiled surface (recommended specific weight between 20 and $40 \mathrm{~g} / \mathrm{m}^{2}$ ), plus a chopped glass 


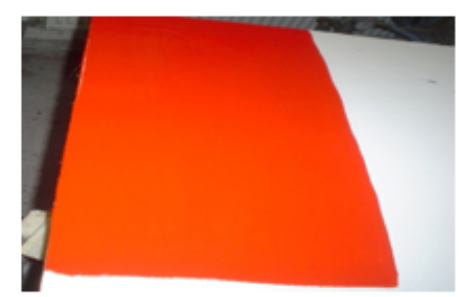

a.

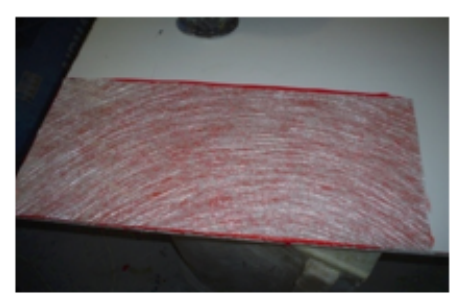

d.

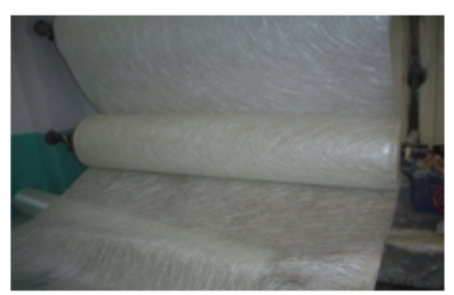

b.

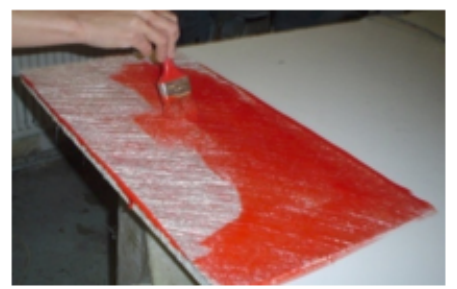

e.

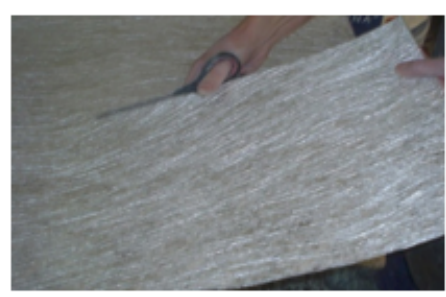

c.

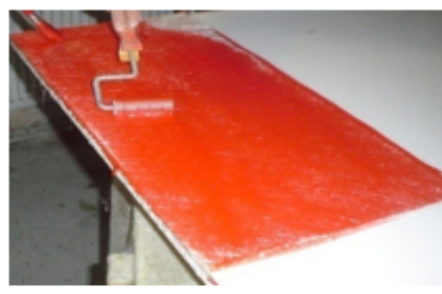

f.

Fig. 1 Stages of obtaining a composite sandwich panel:

a - applying the gelcoat; b - choosing the Stratimat fibre; c - cutting-to-size fiber layer; $\mathrm{d}$ - applying the first Stratimat sheet on the stand;

e - prepregging with epoxy; $f$ - the evenness of the gelcoat

fibre matt layer of 300 or $450 \mathrm{~g} / \mathrm{m}^{2}$ with ancolant pow der. It must be applied immediately after the gelcoat layer has been hardened, that is after at least $2 \mathrm{~h}$, or up to $6 \mathrm{~h}$. Gelcoat is a special unsaturated polyester resins-based substance (a mixture of Nestrapol with talcum powder), with a low lead content, which may be even excluded.

It is recommended to apply layers of equal thickness and without the accumulation of large quantities of gelcoat and for an easier unravelling it is used an appropriate proportion of methyl ethyl ketone peroxide (MEKP) recommended catalyst, (fig. 1).

Apply the resin by spraying over the hardened gelcoat or with a brush or a fur roller (paint roller) with a length of 20 $\mathrm{mm}$. It must be applied as a thick and smooth layer, if possible, double in weight, compared to the reinforcement material used.

Before prepregging, preparations are being made for using the reinforcement material under safe and economically efficient use.

The same method is used to planish the second layer, except this time shall be used Stratimat of $450 \mathrm{~g} / \mathrm{m}$. The soldered joint between the pieces of Stratimat in this layer and the following must be made with an overlap of approximately $5 \mathrm{~cm}$. Repeat this operation for each layer. The surface layer must be formed, at the end, of gelcoat plus six resin and mat layers, with a total thickness of approximately $3 \mathrm{~mm}$.

\section{Determining the thermal characteristics of composite} sandwich structures

To study the thermal behavior of sandwich composite structures, thermal conductivity and thermal resistance are analyzed. The sample under test is placed between a hot plate and the heat flowmeter which is attached to a cold plate. The apparatus is surrounded by insulation.

The hot and cold plates are maintained at suitable constant temperatures, measured by surface thermocouples. A calibration constantfor the individual apparatus is derived from testing a sample of known constant thermal conductivity. By measuring the heat flow meter output and the mean temperature of the test sample, the thermal conductivity is calculated using this calibration constant [14]. The Hilton B480 unit is based on the heat flow meter method described. ISO 8301:1991 [8] gives the range of sample sizes that can be used with this method of conductivity measurement. The Hilton B480 unit is capable of holding samples of $300 \times 300 \mathrm{~mm}$ and $75 \mathrm{~mm}$ thickness, (fig. 2).
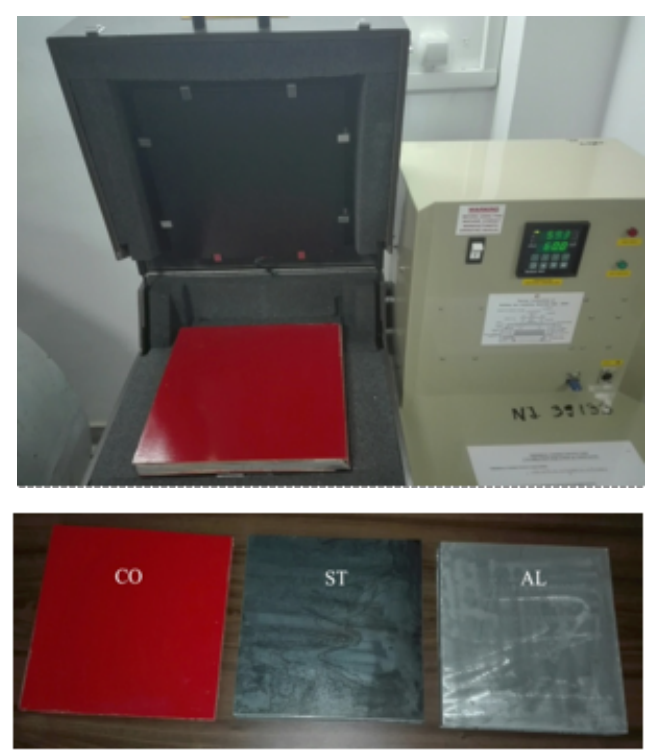

Fig. 2 The Hilton B480 unit and samples 300×300×26 mm

\section{Results and discussions}

The Fourier equation (1) provides the relationship between the parameters of the test samples and the sections.

$$
q=\lambda \cdot A \cdot \frac{\Delta T}{\Delta x}(1)
$$

where: $q[\mathrm{~W}]$ and $T[\mathrm{~K}]$ are the heat flow and temperature difference across the sample, respectively, $A\left[\mathrm{~m}^{2}\right]$ is the area through which the heat flows, $x[\mathrm{~m}]$ is the thickness and $\lambda[\mathrm{W} / \mathrm{mK}]$ is the thermal conductivity of samples.

The thermal conductivity $\lambda$ is determined with equation [15]:

$\lambda=\frac{x \cdot\left[\left(k_{1}+\left(k_{2} \cdot \bar{T}\right)\right)+\left(\left(k_{3}+\left(k_{4} \cdot \bar{T}\right)\right) \cdot H F M\right)+\left(\left(k_{5}+\left(k_{6} \cdot \bar{T}\right)\right) \cdot H F M^{2}\right)\right]}{\Delta T}$

where: $x[m]$ is the sample thickness, $k 1, k 2, k 3, k 4, k 5$, $\mathrm{k} 6$, are calibration constants, HFM [mV] heat flowmeter output, $\bar{T}[\mathrm{~K}]$ is the mean temperature and $\Delta \mathrm{T}[\mathrm{K}]$ is the temperature difference between the hot plate temperature and the cold plate temperature.

In the measurement, upper and lower plates were constantly heated at $60^{\circ} \mathrm{C}$ and cooled at $20^{\circ} \mathrm{C}$, respectively, table 1. 


\begin{tabular}{|c|c|c|c|c|}
\hline $\begin{array}{c}\text { Item } \\
\text { No. }\end{array}$ & Sandwich material & $\begin{array}{c}\text { Dimension } \\
{[\mathrm{mm} \times \mathrm{mm}]}\end{array}$ & $\begin{array}{c}\text { Heat conductivity } \\
\lambda[\mathrm{W} / \mathrm{mK}]\end{array}$ & $\begin{array}{c}\text { Thermal resistence } \\
\mathrm{R}\left[\mathrm{m}^{2} \mathrm{~K} / \mathrm{W}\right]\end{array}$ \\
\hline 1 & Steel-foam-Steel & $300 \times 300$ & 0.043 & 0.604 \\
\hline 2 & Al-foam-Al & $300 \times 300$ & 0.049 & 0.53 \\
\hline 3 & Poly-foam-Poly & $300 \times 300$ & 0.036 & 0.722 \\
\hline
\end{tabular}

Table 1

DIMENSIONS AND THERMAL PROPRETIES OF SANDWICH STRUCTURES

\section{Numerical analysis}

The ûnite element analysis is conducted using commercial soft-ware COSMOS-M. Plane stress condition is assumed during the simulations. The models are meshed with 4-node prismatic elements.

Considering the non-linear behavior of the materials of the core, all simulations have been performed by means of non-linear analyses. As an example, figure 3 shows the meshed and numerical model (1040 elements) used to simulate the tests. The specimen is simply supported at distance of $160 \mathrm{~mm}$. The thermal field is considered as thermal flow on the both face sheets as are presented in table 2.

The specimens are entitled according to the geometrical dimensions, type of material and type of loading, as are specified in table 3.

Whereas in figure 4, 6, 8, 10 and 5, 7, 9, 11 are shown the maps of displacements and stresses corresponding to midspan load, respectivelly.

In tables 4 and 5, the results obtained for maximum displacements and von Mises stresses for specimens type $\mathrm{S} 1$ and ST1 are presented.

\begin{tabular}{|c|c|c|}
\hline T [degree] & Face 1 & Face 2 \\
\hline T1 [degree] & 20 & -10 \\
\hline T2 [degree] & 20 & 0 \\
\hline T3 [degree] & 20 & 10 \\
\hline
\end{tabular}

Table 2

THERMAL FIELD APPLIED TO THE SANDWICH PANELS

Fig. 3. Numerical model for $20 \mathrm{~mm}$ thickness core and $40 \mathrm{~mm}$ thickness core

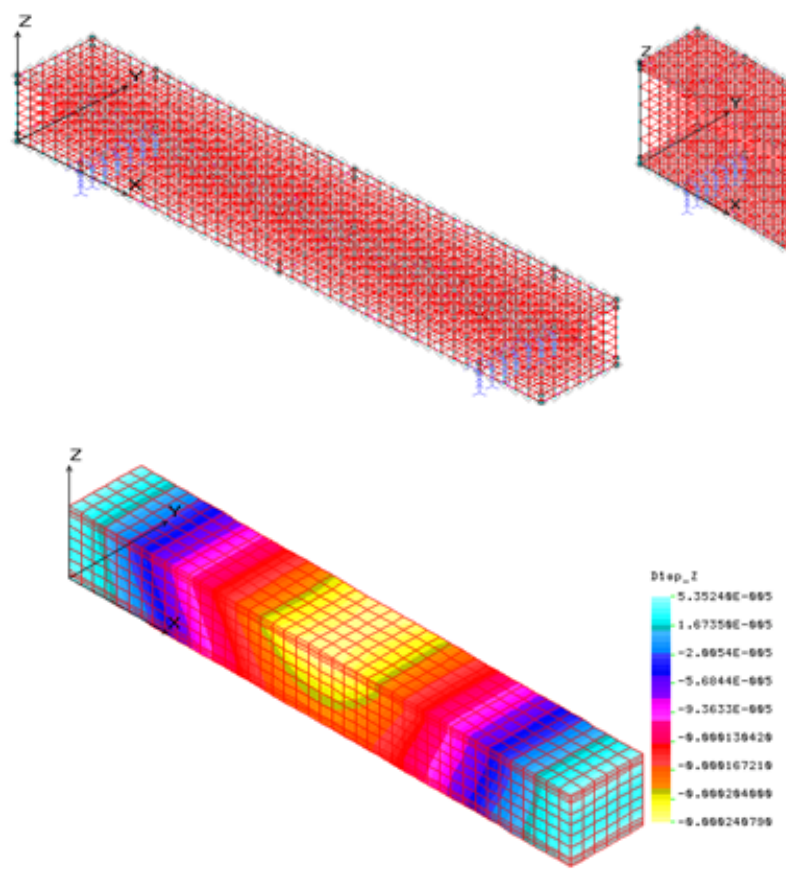

Fig. 4. Displacement map for specimen S1.2
Fig. 5. Von Mises stress map for specimen S1.2

\begin{tabular}{|l|c|c|c|}
\hline \multicolumn{1}{|c|}{ No. } & {$[\mathrm{mm}]$} & & \\
\hline S1.1 & 20 & Steel & 3 points bending \\
\hline S1.2 & 20 & Aluminium & 3 points bending \\
\hline S1.3 & 20 & e-glass polymer & 3 points bending \\
\hline ST1.1 & 20 & Steel & 3 points bending+ thermal field T1, T2, T3 \\
\hline ST1.2 & 20 & Aluminium & 3 points bending+ thermal field T1, T2, T3 \\
\hline ST1.3 & 20 & e-glass polymer & 3 points bending+ thermal field T1, T2, T3 \\
\hline S2.1 & 40 & Steel & 3 points bending \\
\hline S2.2 & 40 & Aluminium & 3 points bending \\
\hline S2.3 & 40 & e-glass polymer & 3 points bending \\
\hline ST2.1 & 40 & Steel & 3 points bending+ thermal field T1, T2, T3 \\
\hline ST2.2 & 40 & Aluminium & 3 points bending+ thermal field T1, T2, T3 \\
\hline ST2.3 & 40 & e-glass polymer & 3 points bending+ thermal field T1, T2, T3 \\
\hline
\end{tabular}

Table 3

SPECIMENSTYPE

Table 4

MAXIMUM DISPLACEMENT AND VON MISES STRESS FOR THE SPECIMENS TYPE S1 FOR STATIC LOAD

\begin{tabular}{|c|c|c|c|}
\hline Structure & Al-Foam-Al & Steel-Foam-Steel & Poly-Foam-Poly \\
\hline w $\max [\mathrm{mm}]$ & 0.2407 & 0.1257 & 0.7723 \\
\hline v.M. stress [MPa] & 17.936 & 21.665 & 6.423 \\
\hline
\end{tabular}




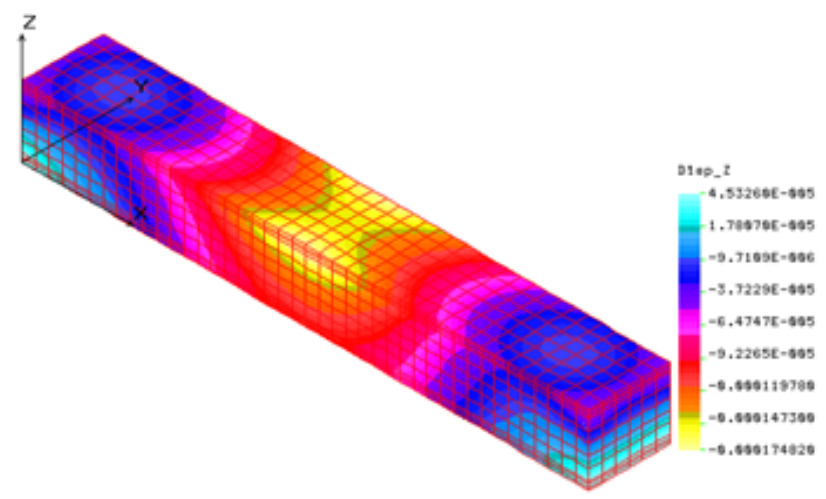

Fig. 6. Displacement map for specimen ST1.2 for T1

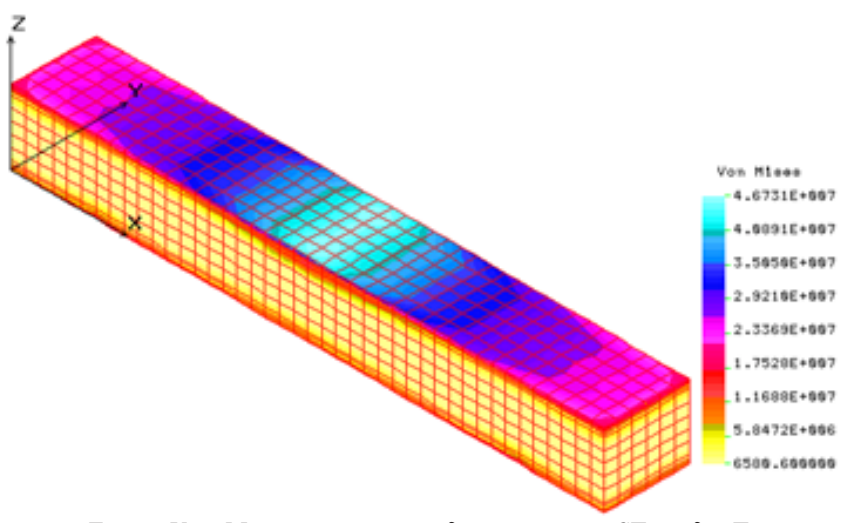

Fig. 7. Von Mises stress map for specimen ST1.2 for T1

Table 5

MAXIMUM DISPLACEMENT AND VON MISES STRESS FOR THE SPECIMENS TYPE ST1 FOR STATIC AND TERMIC LOADING

\begin{tabular}{|c|c|c|c|c|c|c|c|c|c|}
\hline Skin material & \multicolumn{3}{|c|}{ A1-Foam-A1 } & \multicolumn{3}{c|}{ Steel-Foam-Steel } & \multicolumn{3}{c|}{ Poly-Foam-Poly } \\
\hline $\begin{array}{c}\text { Flow } \\
\text { temperature } \\
\text { [deg.] }\end{array}$ & T1 & T2 & T3 & T1 & T2 & T3 & T1 & T2 & T3 \\
\hline $\begin{array}{c}\text { w max } \\
\text { [mm] }\end{array}$ & 0.1748 & 0.1861 & 0.1973 & 0.0595 & 0.0661 & 0.0721 & 0.7486 & 0.7651 & 0.7815 \\
\hline $\begin{array}{c}\text { v.M. stress } \\
{[\mathrm{MPa}]}\end{array}$ & 46.731 & 47.022 & 47.313 & 62.077 & 62.432 & 62.781 & 12.831 & 12.842 & 12.859 \\
\hline
\end{tabular}

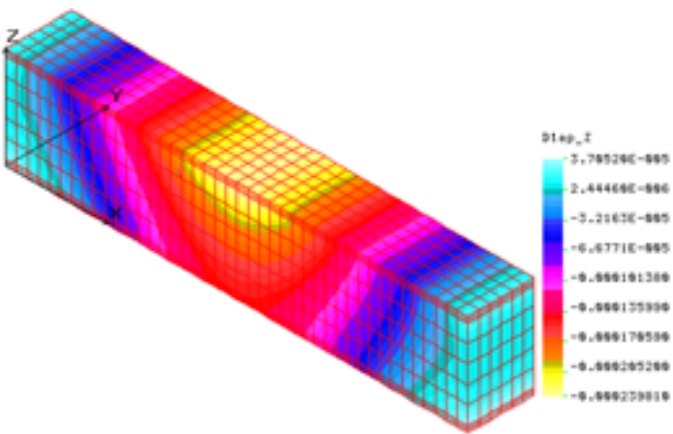

Fig. 8. Displacement map for specimen S2.2

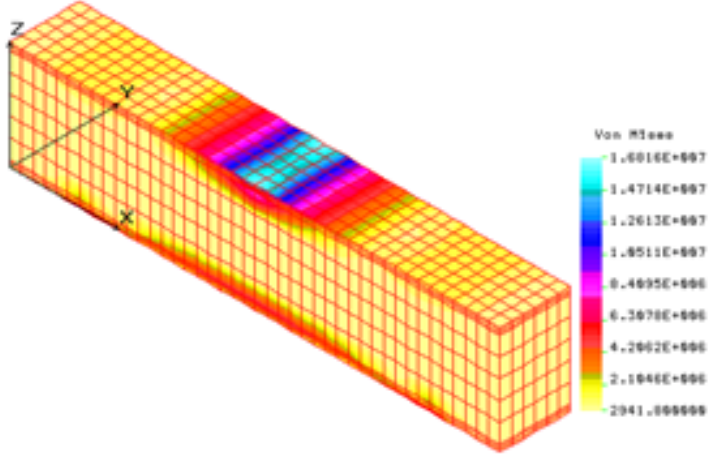

Fig. 9. Von Mises stress map for specimen S2.2

\begin{tabular}{|c|c|c|}
\hline Structure & Al-Foam-Al & Steel-Foam-Steel \\
\hline w max [mm] & 0.2398 & 0.1501 \\
\hline v.M. stress [MPa] & 16.816 & 20.844 \\
\hline \\
\hline
\end{tabular}

Fig. 10. Displacement map for specimen ST2.2 for T1
Table 6 MAXIMUM DISPLACEMENT AND VON MISES STRESS FOR THE SPECIMENS TYPE S2 FOR STATIC LOAD

5.481

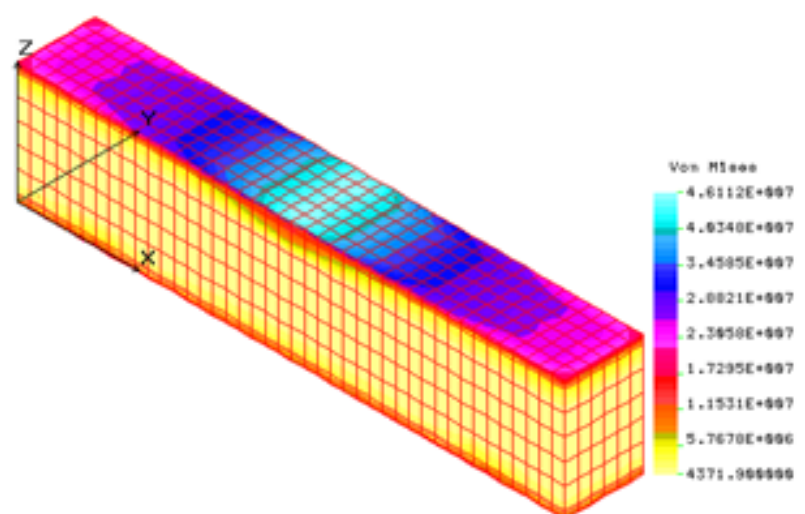

Fig. 11. Von Mises stress map for specimen ST2.2 for T1

Table 7

MAXIMUM DISPLACEMENT AND VON MISES STRESS FOR THE SPECIMENS TYPE S2 FOR STATIC AND TERMIC LOADING

\begin{tabular}{|c|c|c|c|c|c|c|c|c|c|}
\hline Skin material & \multicolumn{3}{|c|}{ Al-Foam-Al } & \multicolumn{3}{c|}{ Steel-Foam-Steel } & \multicolumn{3}{c|}{ Poly-Foam-Poly } \\
\hline $\begin{array}{c}\text { Flow } \\
\text { temperature } \\
\text { [deg.] }\end{array}$ & T1 & T2 & T3 & T1 & T2 & T3 & T1 & T2 & T3 \\
\hline $\begin{array}{c}\text { w max } \\
\text { [mm] }\end{array}$ & 0.1555 & 0.1671 & 0.1774 & 0.0891 & 0.0310 & 0.0960 & 0.4896 & 0.5062 & 0.5188 \\
\hline $\begin{array}{c}\text { v.M. stress } \\
\text { [MPa] }\end{array}$ & 46.112 & 46.289 & 46.466 & 61.220 & 61.450 & 61.672 & 12.279 & 12.284 & 12.291 \\
\hline
\end{tabular}


In tables 6 and 7, the results obtained for maximum displacements and von Mises stresses, respectively, for specimens type S2 and ST2 are presented.

\section{Conclusions}

The influence of the temperature on the flexural behavior of a composite sandwich beam has been studied. In the present work, the actual mechanical behavior in presence of the termic field of the various types of sandwich structures have been investigated. The deflection results show that the specimens with metalic skins of sandwich composite panels got minimum deflection as compare to the composite skins. The contribution of the core thickness is to be included to determine the overall performance of the sandwich composite beams. The results of this study showed the high potential of these types of sandwich composite beam for structural laminated panels. An increase in flexural stiffness due to sandwich effect suggest the application of sandwich composite beam in the outer most layers to carry tensile and compressive stresses, since they are used as thermic insulations.

As a result of static modeling, it can be noticed that the von Mises stress also increases to the increasing of the temperatuses difference of thermal field, having low value in the case of a test-piece made of composite sandwichtype panel with upper made of composite and high value in the case of the sample made of sandwich-type composite with faces made of steel.

Also, a change in the materials of the skins offers a higher stiffness of the panel, but with the addition of a heavier weight than in the case of polymeric structures.

Since the core thickness was increased, the flexural stiffness has increased due to which deflection is reduced, for the same skins type.

Thermal analysis shows different behaviour of composite sandwich-type panels in terms of temperature distribution on thickness of layer structures. From measurements made, the composite panel with the structure: Poly-foam-Poly presents low thermal conductivity and high thermal resistance, compared to the other two structures. For all structures, the highest temperature is at the core of the polystyrene, which is characterised bylow conductivity. Thus, the sandwich-type structures with faces made of composite are recommended to be used as insulating material, in various applications, at low temperatures.

It remains, however, the obvious conclusion that sandwich structures, in most applications, have a greater stiffness and a better thermal insulation, compared with conventional materials.

\section{References}

1. FROSTIG, Y., THOMSEN, O.T., Non-linear thermal response of sandwich panels with a flexible core and temperature dependent mechanical propertie's Composites: Part B, Vol. 39, pp. 165-184, 2008. 2. VINSON, J.R., Sandwich Structures: Past, Present, and Future Sandwich Structures 7: Advancing with Sandwich Structures and Materials, Springer, Dordrecht, pp. 3-12, ISBN 978-1-4020-3444-2, 2005. 3. RAYJ ADE, G.R., SESHAGIRI RAO, G.V.R., Study of Composite Sandwich Structure and Bending Characteristics -A Review, International J ournal of Current Engineering and Technology, Vol. 5(2), pp. 797-802, 2015. 4. KRZYZAK, A., MAZUR, M., GAJEWSKI, M., DROZD, K., KOMOREK, A., PRZYBY£EK, P., Sandwich Structured Composites for Aeronautics: Methods of Manufacturing Affecting Some Mechanical Properties, Internat. Journal of Aerospace Engineering, Vol. 2016(4), pp. 1-10, 2016.

5. FROSTIG Y., THOMSEN O.T., Title thermal buckling and postbuckling of sandwich panels with a transversely flexible core AIAA J ournal, 46 (8), pp. 1976-1989, 2008.

6. QUINTANA, J.M., MOWER, T.M., Thermomechanical behavior of sandwich panels with graphitic-foam cores, Materials $\&$ Design. Vol. 135, pp. 411-422, 2017.

7. XINYU, F., YUBIN, L., JUAN, L., CHUN, Y., KE, L., Modeling of Heat Conduction in Thermoplastic Honeycomb Core/Face Sheet Fusion Bonding, Chinese Journal of Aeronautics, Vol. 22, pp. 685-690, 2009. 8. ISO 8301:1991. Thermal Insulation - Determination of Steady-State Thermal Resistance and Related Properties - Heat Flow Meter Apparatus.

9. VITALE, J.P., FRANCUCCI, G., STOCCHI, A., Thermal conductivity of sandwich panels made with synthetic and vegetable fiber vacuuminfused honeycomb cores, Journal of Sandwich Structures and Materials, Vol. 19(1), pp. 66-82, 2017.

10. ARBAOUI, J., SCHMITT, Y., PIERROT, J.L., ROYER, F.X., Effect of Core Thickness and Intermediate Layers on Mechanical Properties of Polypropylene Honeycomb Multi-Layer Sandwich Structures, Archives of Metallurgy and Materials, Vol. 59(1), pp. 11-16, 2014.

11. SHEN, Y., MCKOWN, S., TSOPANOS, S., SUTCLIFFE, C.J ., MINES R.A.W., CANTWELL, W.J., The Mechanical Properties of Sandwich Structures Based on Metal Lattice Architectures, J ournal of Sandwich Structures and Materials, Vol. 12, pp. 159-180, 2010.

12. CONSTANTINESCU, I.N., PICIU, R.C., HADAR, A., GHEORGHIU, H., Rezistenta materialelor pentru inginerie mecanica, Ed. BREN, Bucuresti, 2006.

13. BEZNEA, E.F., CHIRICA, I., BAROIU, N., TEODOR, V.G., Parametric study of experimental and numerical simulation of sandwich composite structures flexural behaviour, Mat. Plast., 54, no. 4, p. 682$688,2017$.

14. ${ }^{* * *}$ Hilton 480 unit Instruction manual.

Manuscript received: 19.12 .2018 